\title{
Oxymatrine Downregulates HPV16E7 Expression and Inhibits Cell Proliferation in Laryngeal Squamous Cell Carcinoma Hep-2 Cells In Vitro
}

\author{
Xin-Jiang Ying, Bin Jin, Xin-Wei Chen, Jin Xie, Hong-Ming Xu, and Pin Dong \\ Department of Otolaryngology-Head and Neck Surgery, Shanghai First People's Hospital, Shanghai Jiao Tong University, \\ Shanghai 200080, China
}

Correspondence should be addressed to Xin-Jiang Ying; yingxinjiang@126.com and Pin Dong; dongpin64@aliyun.com

Received 9 November 2014; Revised 31 January 2015; Accepted 6 February 2015

Academic Editor: Akio Hiura

Copyright (C) 2015 Xin-Jiang Ying et al. This is an open access article distributed under the Creative Commons Attribution License, which permits unrestricted use, distribution, and reproduction in any medium, provided the original work is properly cited.

\begin{abstract}
Objective. To investigate the possible mechanisms of oxymatrine's role in anti laryngeal squamous cell carcinoma. Methods. We examined the effects of oxymatrine on the proliferation, cell cycle phase distribution, apoptosis, and the protein and mRNA expression levels of HPV16E7 gene in laryngeal carcinoma Hep-2 cells in vitro. The HPV16E7 siRNA inhibition was also done to confirm the effect of downregulating HPV16E7 on the proliferation in Hep-2 cells. Results. Oxymatrine significantly inhibited the growth and proliferation of Hep-2 cells in a dose-dependence and time-dependence manner. Oxymatrine blocked Hep-2 cells in G0/G1 phase, resulting in an obvious accumulation of G0/G1 phase cells while decreasing S phase cells. Oxymatrine induced apoptosis of Hep- 2 cells, whose apoptotic rate amounted to about $42 \%$ after treatment with $7 \mathrm{mg} / \mathrm{mL}$ oxymatrine for $72 \mathrm{~h}$. Oxymatrine also downregulated the expression of HPV16E7 gene, as determined by the western blotting and reverse transcriptionpolymerase chain reaction analysis. Knockdown of HPV16E7 effectively inhibited the proliferation of Hep-2 cells. Conclusions. Oxymatrine inhibits the proliferation and induces apoptosis of laryngeal carcinoma Hep-2 cells, which might be mediated by a significant cell cycle arrest in G0/G1 phase and downregulation of HPV16E7 gene. Oxymatrine is considered to be a likely preventive and curative candidate for laryngeal cancer.
\end{abstract}

\section{Introduction}

Laryngeal squamous cell carcinoma is a common malignancy in the head and neck region [1]. In addition to the wellestablished risk factors for laryngeal cancer such as tobacco smoking and alcohol consumption, a number of studies suggest that human papillomavirus type 16 (HPV16) is also associated with the development of laryngeal cancer [24]. Carcinogenesis by HPV16 is primarily attributed to the continuous expression of viral protein $E 6 / E 7$, which results in cellular resistance to apoptosis and cancer formation by, respectively, interacting with $p 53$ and $p R b$ in cell cycle checkpoint [5-7]. We have also demonstrated that the overexpression of HPV16E7 oncoprotein is associated with the development of laryngeal cancer [8]. Therefore, the HPV16E7 oncogene is considered to be potential therapeutic target for blocking the development of laryngeal cancer.
Treatment strategies for laryngeal cancer today are focused on larynx preservation which have the aim to preserve not only the anatomic organ, but, more importantly, also its function [9]. To achieve organ preservation, various options for treatment modalities including radiotherapy, chemotherapy, and targeted molecular therapies have been added to the conventional approaches of surgery [10]. Although a number of chemotherapeutic drugs are available for the treatment of cancer, which can be used for controlling the growth of cancer and have received certain curative efficacy, the side effects limit their application. Therefore, to discover novel natural substances that have therapeutic selectivity without significant toxicity to normal cells is an important tendency for laryngeal cancer therapy. Oxymatrine is one of the quinolizidine alkaloids extracted from the root of traditional Chinese herbal medicine Sophora japonica (Sophora flavescens Ait). It has been reported that oxymatrine 
plays important roles in anti-inflammation, inhibition of immune reaction, antivirus, antitumors, and so on [11-14]. Different from the usual chemotherapy medicine, oxymatrine has the selectivity kill capability to the tumor cells, with little influence to some normal cells [15].

To our knowledge, there are few studies on the application of oxymatrine in the treatment of laryngeal cancer. Similarly, there currently is no report concerning the mechanism of oxymatrine and its putative relationship with HPV16E7. In the present study, we investigated the effects of oxymatrine on laryngeal squamous cell carcinoma Hep- 2 cells by examining cell proliferation, cell cycle phase distribution, apoptosis, and the protein and mRNA expression levels of HPV16E7 gene in vitro. This study aimed to explore the antitumor mechanisms of oxymatrine and provide experimental evidence for the application of oxymatrine in the prevention and treatment of laryngeal squamous cell carcinoma.

\section{Materials and Methods}

2.1. Oxymatrine. Oxymatrine $(300 \mathrm{mg} / \mathrm{mL})$ was purchased from Chia Tai Tianqing Pharmaceutical Group Co., Ltd., Nanjing (Jiangsu, China). In the experiment, we used the same batch of oxymatrine, whose purity is more than $99 \%$ indicated by SDS-PAGE analysis.

2.2. Cell Line and Culture. The Hep-2 human laryngeal carcinoma cell line was obtained from the American Type Culture Collection (ATCC, Manassas, VA, USA). Cells were routinely cultured in Dulbecco's modified Eagle's medium (DMEM; Gibco Corporation, Carlsbad, CA, USA) supplemented with $10 \%$ fetal bovine serum (FBS; Sijiqing, China), $100 \mathrm{U} / \mathrm{mL}$ penicillin $\mathrm{G}$, and $100 \mathrm{U} / \mathrm{mL}$ streptomycin (Gibco, Carlsbad, CA, USA) in a humidified atmosphere of $95 \%$ air and $5 \% \mathrm{CO}_{2}$ at $37^{\circ} \mathrm{C}$. The medium was changed every 3 days.

2.3. Proliferation Assay. Hep-2 cells in logarithmic growth phase were seeded in 96-well microplates with $1 \times 10^{5}$ each well and cultured cells with DMEM growth medium for $24 \mathrm{~h}$. Then the medium was replaced with DMEM growth medium containing various concentrations of oxymatrine $(3,5$, and $7 \mathrm{mg} / \mathrm{mL}$ ) and cultured continuously. In addition, control cells were incubated with medium only. After exposure to oxymatrine, changes of cell morphology were observed by optical microscope (Olympus, Japan) and the proliferation of Hep-2 cells was assessed by using CCK-8 assay. After 24, 72,120 , and $168 \mathrm{~h}$, cells were treated with $10 \mu \mathrm{L}$ of CCK-8 reagent (Dojindo Molecular Technologies, Kunamoto, Japan) and incubated at $37^{\circ} \mathrm{C}$ for $1 \mathrm{~h}$. An automatic microtiter plate reader was set to zero according to the control wells. The absorbance $(A)$ of each well was measured at a wavelength of $450 \mathrm{~nm}$. The rate of inhibition was calculated as follows: cell proliferation inhibition $(\%)=(1-$ average absorbance $(A)$ of the experimental group/average absorbance $(A)$ of the control group) $\times 100 \%$.

2.4. Cell Cycle Analysis. After preincubation with DMEM growth medium for $24 \mathrm{~h}$, Hep-2 cells were exposed to medium containing different concentrations of oxymatrine
$(0,3,5$, and $7 \mathrm{mg} / \mathrm{mL})$ for $72 \mathrm{~h}$. The cells were harvested by centrifugation, fixed in $70 \%$ cooled ethanol, and then dyed with propidium iodide (PI) for $30 \mathrm{~min}$. DNA content was detected by a flow cytometer (FACSCaliburTM, America $\mathrm{BD})$. The relative proportions of cells in the individual cell-cycle phase fraction were determined from the flow cytometry data.

2.5. Apoptosis Assay. All the operations were based on instructions which are described as manual of cell apoptosis assay kit. After treatment with various concentrations of oxymatrine $(0,3,5$, and $7 \mathrm{mg} / \mathrm{mL})$ for $72 \mathrm{~h}$, Hep- 2 cells were harvested by centrifugation, resuspended in binding buffer, and successively incubated with $5 \mu \mathrm{L}$ of Annexin V-FITC and $5 \mu \mathrm{L}$ of PI (Multi Sciences, China) for $15 \mathrm{~min}$ at room temperature. Apoptosis was determined by flow cytometric analysis using a flow cytometer (FACSCaliburTM, America BD).

2.6. Real-Time PCR. Total RNA was extracted from Hep2 cells treated with $5 \mathrm{mg} / \mathrm{mL}$ of oxymatrine for $72 \mathrm{~h}$ or the control cells using Trizol reagent (Invitrogen, Shanghai, China) and converted to cDNA using MMLV reverse transcriptase kit (Promega, USA). Aliquots of cDNA were subjected to quantitative real-time PCR using Step One Plus Real-time PCR system (Applied Biosystems, USA). The mRNA levels were normalized to that of $\beta$-actin. The specific primer pairs were as follows: HPV16E7, sense: $5^{\prime}-$ CGGGATCCATGCATGGAGATACA- $3^{\prime}$ and antisense: $5^{\prime}$ GCGGGCCCTTATGGTTTCTGAGA-3'; $\beta$-actin, sense: $5^{\prime}$-CATGTACGTTGCTATCCAGGC- $3^{\prime}$ and antisense: $5^{\prime}$ CTCCTTAATGTCACGCACGAT- $3^{\prime}$. Data were analyzed using the $2^{-\Delta \Delta C t}$ method.

2.7. Western Blot Analysis. The protein was extracted from Hep- 2 cells treated with $5 \mathrm{mg} / \mathrm{mL}$ of oxymatrine for $72 \mathrm{~h}$ or the control cells. Cell extracts were prepared in radioimmunoprecipitation assay buffer $(150 \mathrm{mM} \mathrm{NaCl}, 0.1 \%$ SDS, $0.5 \%$ sodium deoxycholate, $1 \%$ Nonidet P- 40 , and $50 \mathrm{mM}$ Tris, $\mathrm{pH} 8.0$ ), with the addition of $2 \mathrm{mM}$ phenylmethylsulfonyl fluoride. Lysis buffer was freshly prepared and added in 6-well plates $(100 \mu \mathrm{L} /$ well) on ice, which were then incubated for $10 \mathrm{~min}$. Protein concentrations were determined by protein assay kit. Equal amounts of proteins $(10 \mu \mathrm{g}$ per condition) were boiled for $10 \mathrm{~min}$ in loading buffer before being separated on $15 \%$ SDS-PAGE gels. Separated proteins were transferred to polyvinylidene difluoride membranes at $100 \mathrm{~V}$ for $1 \mathrm{~h}$ before membrane blocking in PBS with 5\% skim milk powder and Tween 20. Anti-HPV16E7 primary antibody (Biorbyt) and secondary antibodies (Abcam) were diluted by 1/500 with PBST buffer and incubated for $60 \mathrm{~min}$ at room temperature. Membrane was washed for 3 times by PBST before each step. Protein bands were visualized by enhanced chemiluminescence. $\beta$-actin was used as an internal control.

2.8. RNA Interference. The RNAi sequence for HPV16E7 (GCT TCG GTT GTG CGT ACA A) was identified by using the manufacturer's RNAi Designer programme, and the negative control having no homology with human genome 


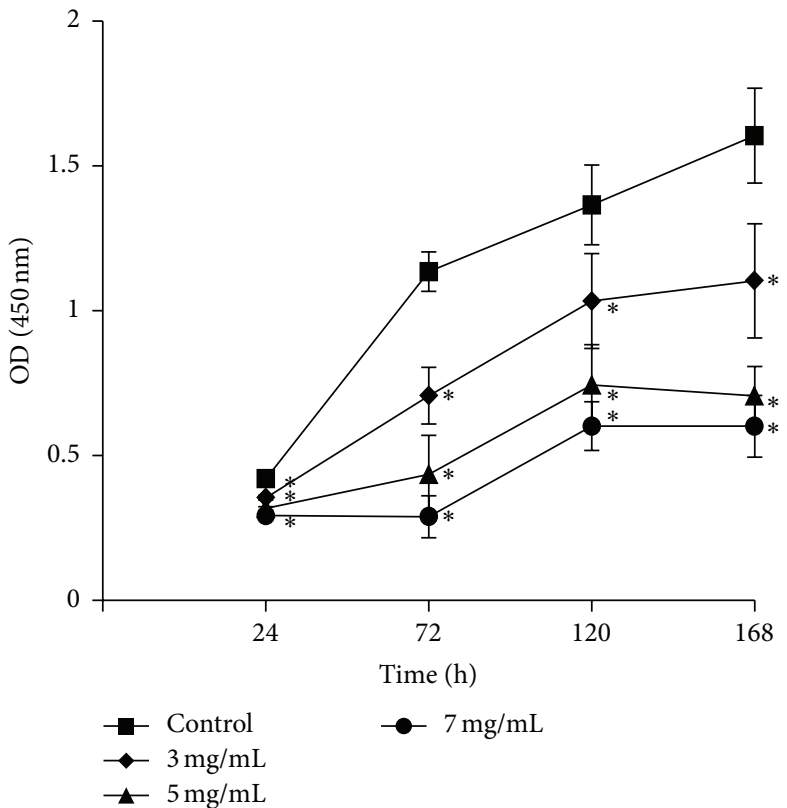

(a)
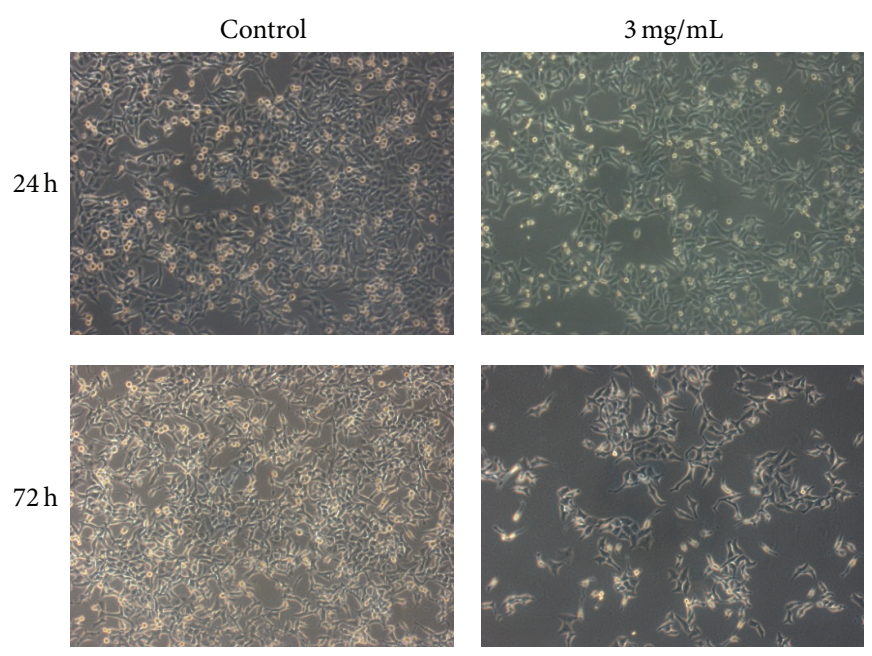

(c)

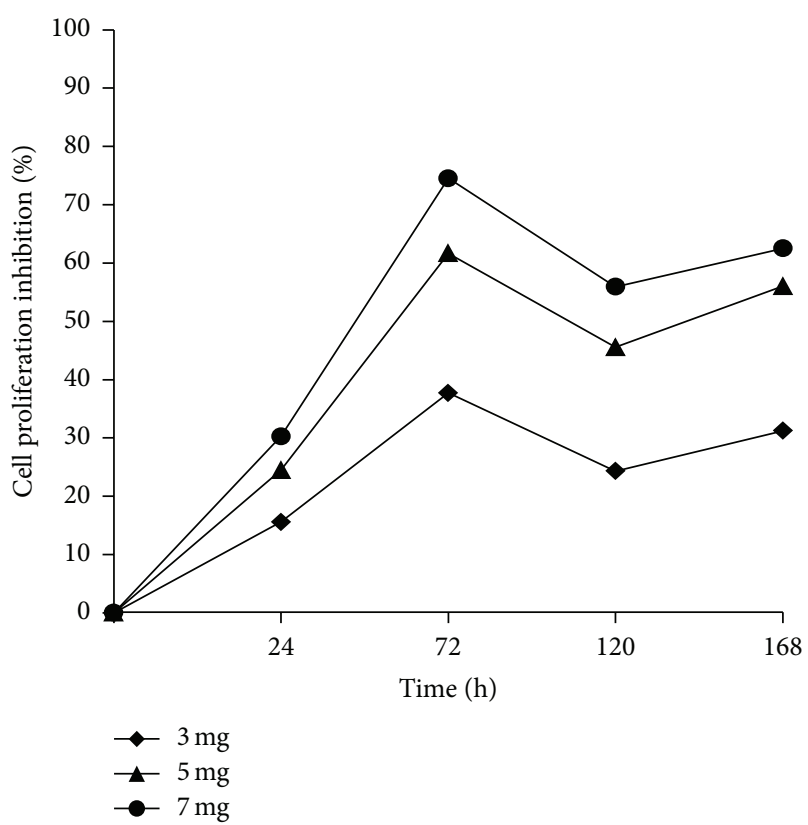

(b)
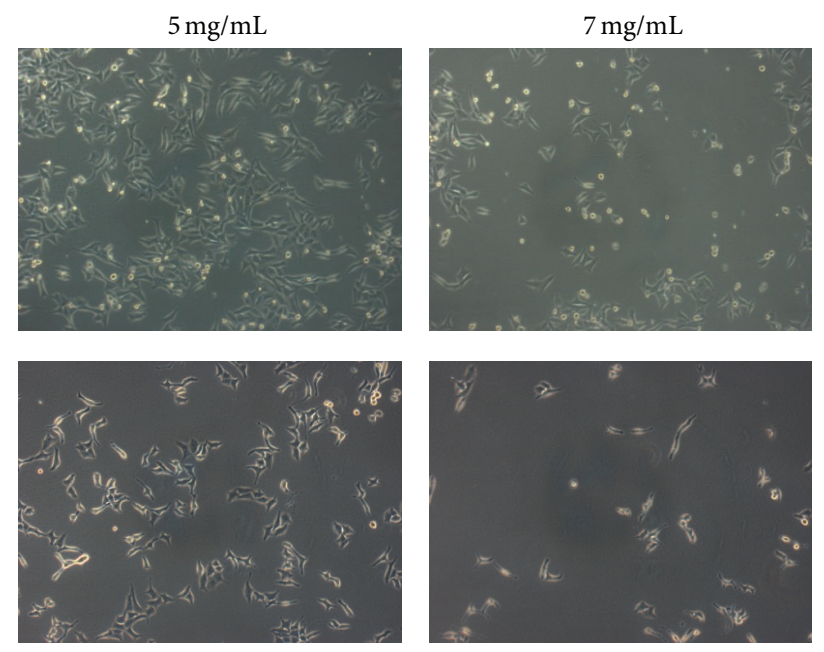

FIGURE 1: Effects of oxymatrine on proliferation of Hep-2 cells. (a) Hep-2 cells were treated with oxymatrine at different concentrations for various times and the OD values were obtained through reading plate at $450 \mathrm{~nm}$ with 96 -well microtest spectrophotometer by CCK- 8 assay. (b) Relationship between the percentage of laryngeal cancer cell proliferation inhibition and different concentrations of oxymatrine. (c) Morphological changes induced by various concentrations of oxymatrine for 24 and $72 \mathrm{~h}$ in Hep-2 cells $(\times 100)$.

was created by a scrambled sequence (TTC TCC GAA CGT GTC ACG T). The siRNA duplex was transfected using Lipofectamine 2000 Reagent (Invitrogen) as recommended by the manufacturer, and the cells were assayed for silencing $72 \mathrm{~h}$ after transfection.

2.9. Statistical Analysis. All experiments were performed in triplicate, and data were shown as the mean \pm SD where they are applicable. Statistically significant differences between groups were determined by one-way ANOVA using SPSS 17.0 software (SPSS, Chicago, IL, USA), and $P<0.05$ was considered statistically significant.

\section{Results}

3.1. Oxymatrine Inhibits the Growth and Proliferation of Hep-2 Cells. To determine whether oxymatrine inhibits the proliferation of Hep-2 cells, we examined the effect of oxymatrine on proliferation of the Hep- 2 cell line by using CCK- 8 assay. We found that oxymatrine significantly inhibited the growth of Hep-2 cells in a concentration-dependence and timedependence manner, compared with that in the control cells $(P<0.05$, Figure $1(\mathrm{a}))$. In the group treated with $3 \mathrm{mg} / \mathrm{mL}$ of oxymatrine at the indicated time points of $24,72,120$, and $168 \mathrm{~h}$, the percentage of Hep- 2 cell proliferation inhibition 

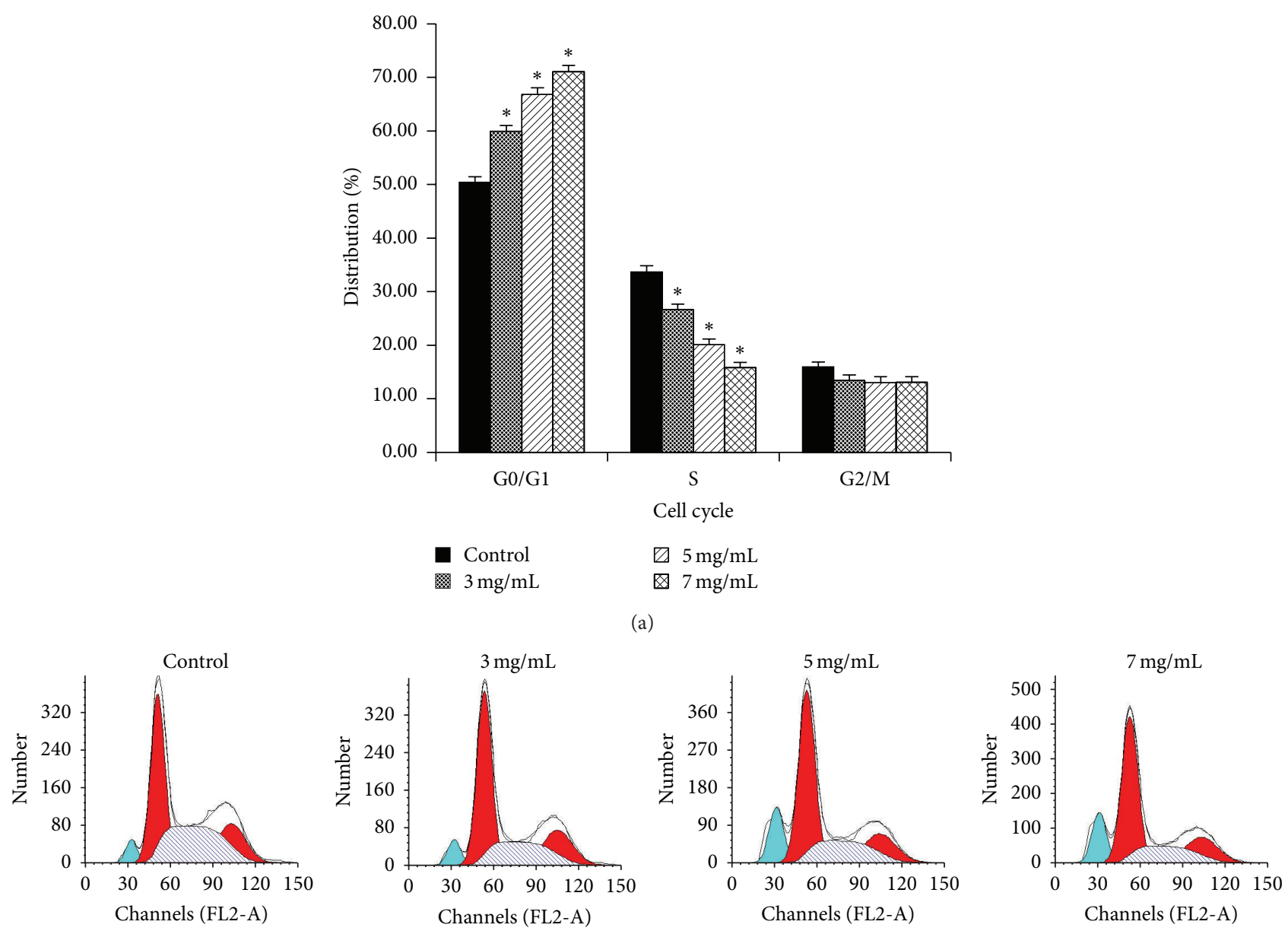

(b)

FIGURE 2: Changes of cell cycle distribution in Hep-2 cells after treatment with oxymatrine at different concentrations for $72 \mathrm{~h}$. (a) Oxymatrine increased the proportion of cells in G0/G1 phase and decreased that in the S phase, compared with the control group $\left({ }^{*} \mathrm{P}<0.05\right)$. (b) FCM analysis showed oxymatrine arrested Hep-2 cell cycling in the G0/G1 phase.

was $15.6 \%, 37.7 \%, 24.3 \%$, and $31.2 \%$, respectively. Additionally, in the group treated with $5 \mathrm{mg} / \mathrm{mL}$ of oxymatrine, the percentage of cell proliferation inhibition at $24,72,120$, and $168 \mathrm{~h}$ was $24.5 \%, 61.6 \%, 45.5 \%$, and $56.0 \%$, respectively. In the group treated with $7 \mathrm{mg} / \mathrm{mL}$ of oxymatrine, the percentage of cell proliferation inhibition at $24,72,120$, and $168 \mathrm{~h}$ was $30.2 \%, 74.5 \%, 55.9 \%$, and 62.5\%, respectively (Figure $1(\mathrm{~b})$ ). At $72 \mathrm{~h}$, oxymatrine showed a significantly higher inhibiting effect than that at $24 \mathrm{~h}$. In contrast, there was no significant difference in cell proliferation inhibition among prolonged treatment for $120 \mathrm{~h}$ and $168 \mathrm{~h}$. Therefore, we choose the time point of $72 \mathrm{~h}$ for the further investigation. Besides, we also found that the number of cells decreased with increasing concentrations of oxymatrine under a microscope (Figure 1(c))

3.2. Oxymatrine Arrests Hep-2 Cells in the G0/G1 Phase. To evaluate the effect of oxymatrine on the cell cycle distribution, the FCM analysis was performed. We found that the proportion of G0/G1 phase was $59.91 \pm 1.09 \%, 66.85 \pm 1.18 \%$, and $71.07 \pm 1.12 \%$, respectively, after treatment with 3,5 , and
$7 \mathrm{mg} / \mathrm{mL}$ of oxymatrine for $72 \mathrm{~h}$. For the control group, the percentage of $\mathrm{G} 0 / \mathrm{G} 1$ phase was $50.37 \pm 1.08 \%$. The frequency of Hep-2 cell in G0/G1 phase is significantly increased while that of cells in the S-phase is decreased with the increasing concentration of oxymatrine, as compared with that in the control group $(P<0.05, n=6$, Figure 2$)$. These data indicated that oxymatrine arrested cell cycle of Hep- 2 cells in $\mathrm{G} 0 / \mathrm{G} 1$ phase.

3.3. Oxymatrine Induces Apoptosis of Hep-2 Cells. To further investigate the effects of oxymatrine on cell death of Hep-2 cells, the rate of apoptosis was evaluated by flow cytometry analysis. We found that the apoptosis rate was $29.62 \pm 0.41 \%$, $37.44 \pm 0.38 \%$, and $42.94 \pm 0.56 \%$, respectively, after treatment with 3,5 , and $7 \mathrm{mg} / \mathrm{mL}$ of oxymatrine for $72 \mathrm{~h}$. For the control group, the apoptosis rate was $11.05 \pm 0.40 \%$. The percentage of apoptosis is significantly increased with the increasing concentration of oxymatrine, as compared with that in the control group ( $P<0.05, n=6$, Figure 3 ). The results demonstrate that suppression of cell proliferation may be caused by cell death resulting from oxymatrine. 


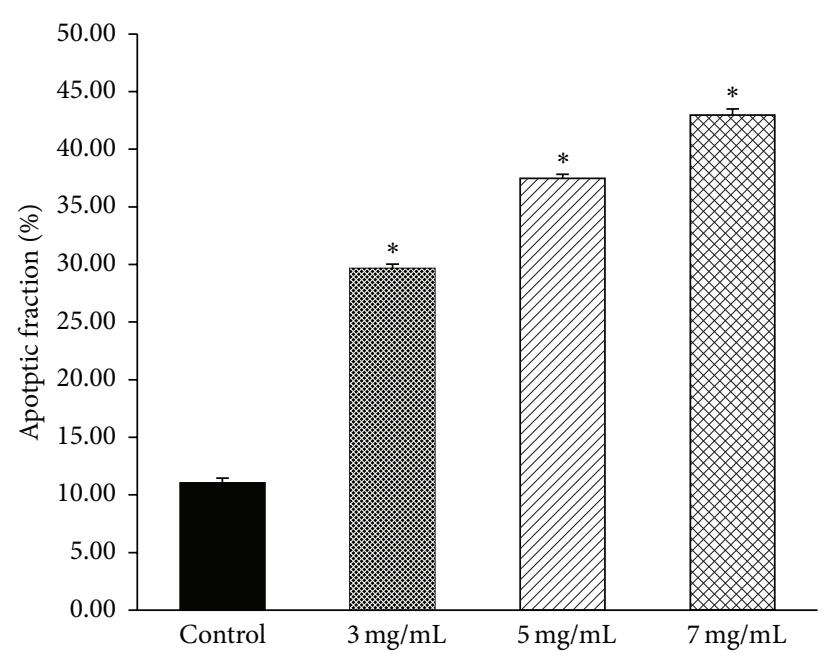

(a)
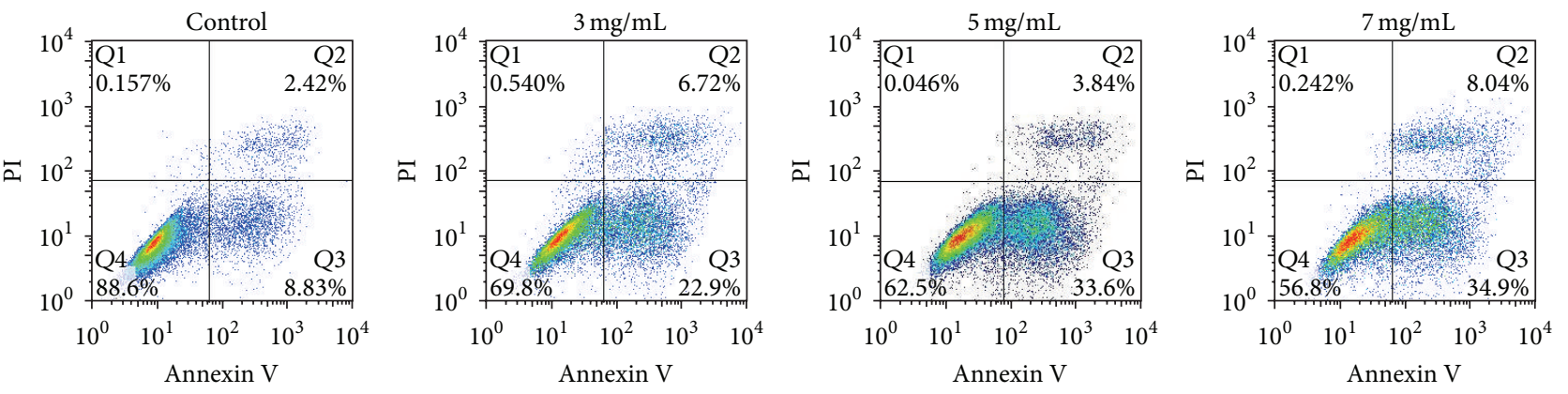

(b)

FIgURE 3: Apoptosis induced by oxymatrine was detected by Annexin V-FITC/PI. (a) Oxymatrine significantly induced cell apoptosis in the treatment group, compared with that in the control group $\left({ }^{*} P<0.05\right)$. (b) FCM data showed that the apoptotic rate of Hep-2 cells treated with oxymatrine was significantly increased.

\subsection{Oxymatrine Downregulates HPV16E7 Expression in Hep-2} Cells. The effect of oxymatrine on the expression of HPV16E7 gene was examined by real-time PCR and Western blot analysis. We found that both mRNA and protein levels of HPV16E7 gene in the Hep-2 cells treated with $5 \mathrm{mg} / \mathrm{mL}$ of oxymatrine were sharply reduced, compared with that in the control group $(P<0.05, n=6$, Figure 4$)$. The mRNA level is decreased by $69.3 \%$, while the protein level is reduced by $56.3 \%$. These data demonstrate that the expression of HPV16E7 gene is efficiently downregulated by oxymatrine in Hep-2 cells.

3.5. Knockdown of HPV16E7 Inhibits the Proliferation of Hep2 Cells. To assess the effect of downregulating HPV16E7 on the proliferation of Hep-2 cells, we knocked down HPV16E7 mRNA transcripts using HPV16E7 siRNA. HPV16E7 siRNA caused over $62.4 \%$ of reduction in HPV16E7 mRNA expression and $52.7 \%$ in protein expression compared to scrambled siRNA (Figures 5(a)-5(c)). After $72 \mathrm{~h}$ of culture, the proliferation inhibition of Hep-2 cells transfected by HPV16E7 siRNA was $62.8 \%$ compared with scramble control $(P<$ 0.05 , Figure $5(d))$. These data indicated that downregulating HPV16E7 inhibited the growth of Hep-2 cells.

\section{Discussion}

Oxymatrine is one of the main alkaloid components in the traditional Chinese herbal medicine Sophora japonica (Sophora flavescens Ait). It is commonly known that oxymatrine exhibits many biological activities and possesses a wide range of pharmacological effects, such as anti-inflammation [16], antifibrosis [17], analgesic [18], immunosuppression [19], and antivirus [20]. Oxymatrine also has been extensively studied, for their cancer chemoprevention potentially against various cancers, for instance, gastric cancer [21], breast cancer [22], hepatocellular carcinoma [23], and pancreatic cancer [24]. However, the mechanisms of the antitumor properties of oxymatrine in laryngeal cancer are not well established to date. In the present study, we treated laryngeal squamous cell carcinoma Hep-2 cells with various concentrations of oxymatrine, to investigate the effect of oxymatrine on the cell proliferation, cell-cycle progression, and apoptosis of laryngeal cancer.

The loss of regulatory control of cell proliferation and apoptosis plays an important role in tumorigenesis. It has been a well-studied area to interfere with the dysfunctions of cell proliferation and apoptosis in cancer research. In this 


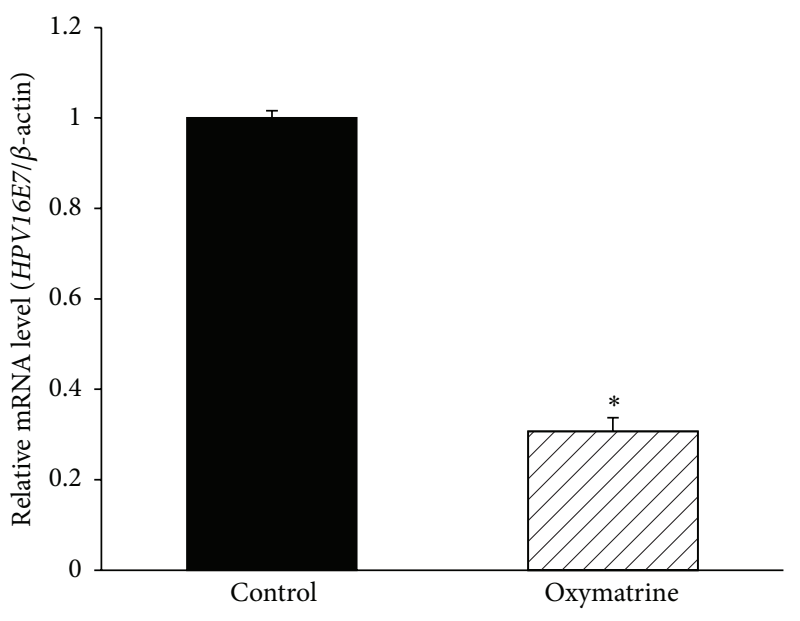

(a)

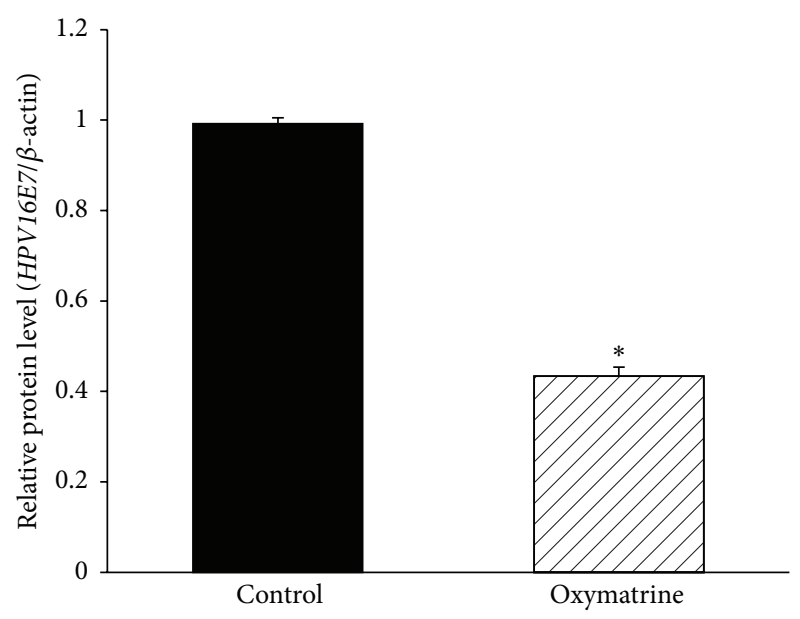

(b)

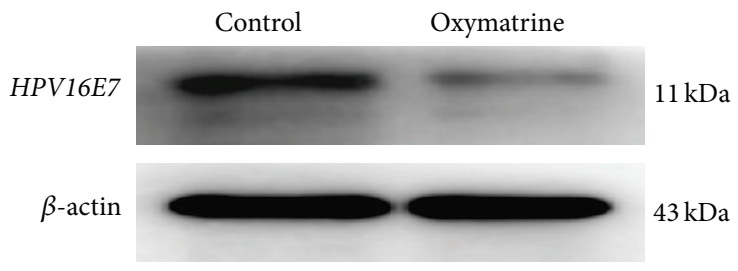

(c)

FIgURE 4: Expressions of HPV16E7 mRNA and protein in Hep-2 cells treated with oxymatrine. (a) The expression levels of HPV16E7 mRNA were assessed by qRT-PCR $\left(2^{-\Delta \Delta \mathrm{Ct}}\right.$ method. $2^{-\Delta \Delta \mathrm{Ct}}$ indicated relative expression level in the treatment group, compared with that in the control group). (b) The protein level of HPV16E7 in the treatment group was significantly reduced, compared with the control group $\left({ }^{*} P<0.05\right)$. (c) The expression levels of HPV16E7 protein were detected by Western blotting.

study, we found that oxymatrine significantly inhibited the growth and proliferation in Hep- 2 cells, which presented a concentration-dependence and time-dependence manner, as determined by the CCK- 8 assay. Not only does the inhibitory mechanism involve alteration of the proliferation of cancer cells, but also induction of apoptosis. From apoptosis assay, we found that oxymatrine induced an obviously apoptosis in Hep- 2 cells, and the apoptotic rate amounted to $42.94 \pm$ $0.56 \%$ after being treated by $7 \mathrm{mg} / \mathrm{mL}$ oxymatrine for $72 \mathrm{~h}$. In general, there is a near correlativity between apoptosis and cell cycle. If cell cycle is blocked in a phase, apoptosis would be appearing in the phase in which cell cycle is arrested. As shown from FCM analysis, oxymatrine significantly blocked the cell cycle of Hep-2 cells in G0/G1 phase, the cells in G0/G1 phase were significantly increased, while the cells in the $S$ phase were decreased with the increasing concentration of oxymatrine, which suggests that apoptosis of Hep-2 cells induced by oxymatrine maybe occurs in G0/G1 phase. One of the basic characteristics of tumor cells is uncontrolled cell growth. The mechanism underlying uncontrolled proliferation is the destruction of the cell cycle control machinery. Regulation of cell cycle progression can potentially trigger cellular apoptosis suppressing cell proliferation to achieve antitumor effects. The results of our study demonstrate that oxymatrine may be a potential chemotherapeutics for the treatment of laryngeal cancer.

Molecular epidemiologic evidences clearly indicate that $H P V 16$ is closely associated with the development of laryngeal cancer, which encodes the E6 and E7 oncogenes, whose expression is essential for virus replication. The viral protein E7 of HPV16 binds to hypophosphorylated members of the retinoblastoma family, resulting in their destabilization and the disruption of $R b / E 2 F$ complexes [25], which repress transcription of genes required for cell cycle progression to allow the progression of cell cycle into $S$ phase [26] and increase antiapoptotic protein $\mathrm{Bcl}-2$ to promote the survival of cells and stimulate cell proliferation [27]. In previous studies, oxymatrine has been demonstrated to exhibit specific pharmacological properties for antihepatitis virus. Although there are no reports on anti-HPV effects of oxymatrine, we found that oxymatrine downregulated the HPV16E7 expression at both mRNA and protein levels. To assess the effect of downregulating HPV16E7 on the proliferation of Hep-2 cells, we also knocked down HPV16E7 mRNA transcripts using HPV16E7 siRNA and found that downregulating HPV16E7 inhibited the growth of Hep-2 cells. Thus, we speculate that oxymatrine may inhibit proliferation of Hep2 cells through downregulation of HPV16E7 gene. In other studies, compounds isolated from arsenic have demonstrated 


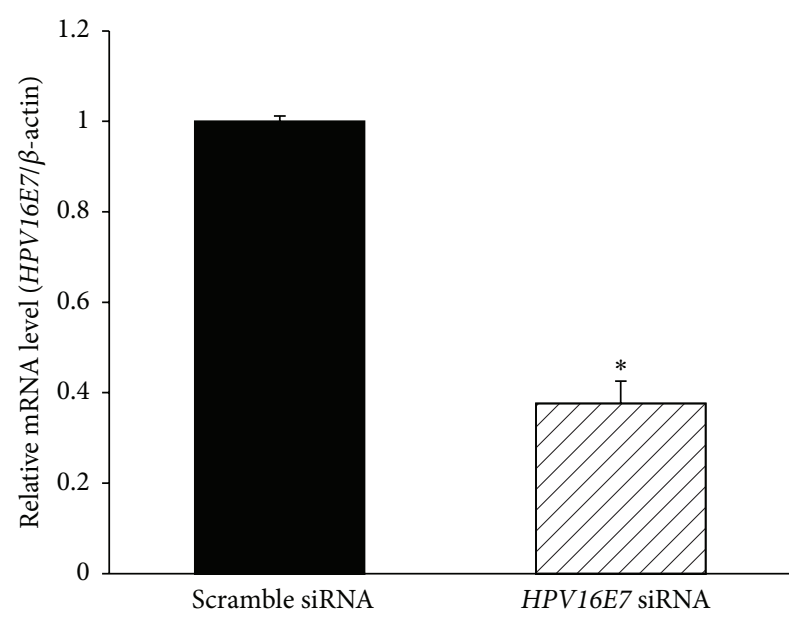

(a)

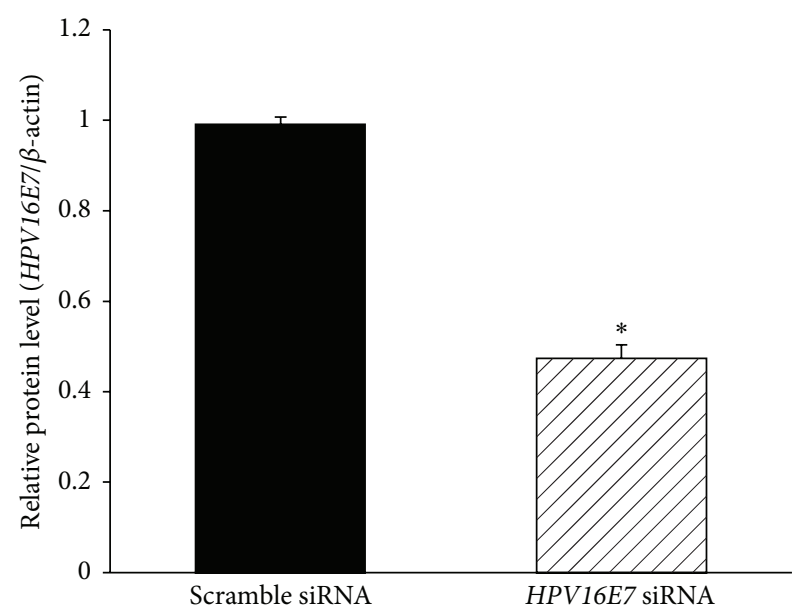

(b)
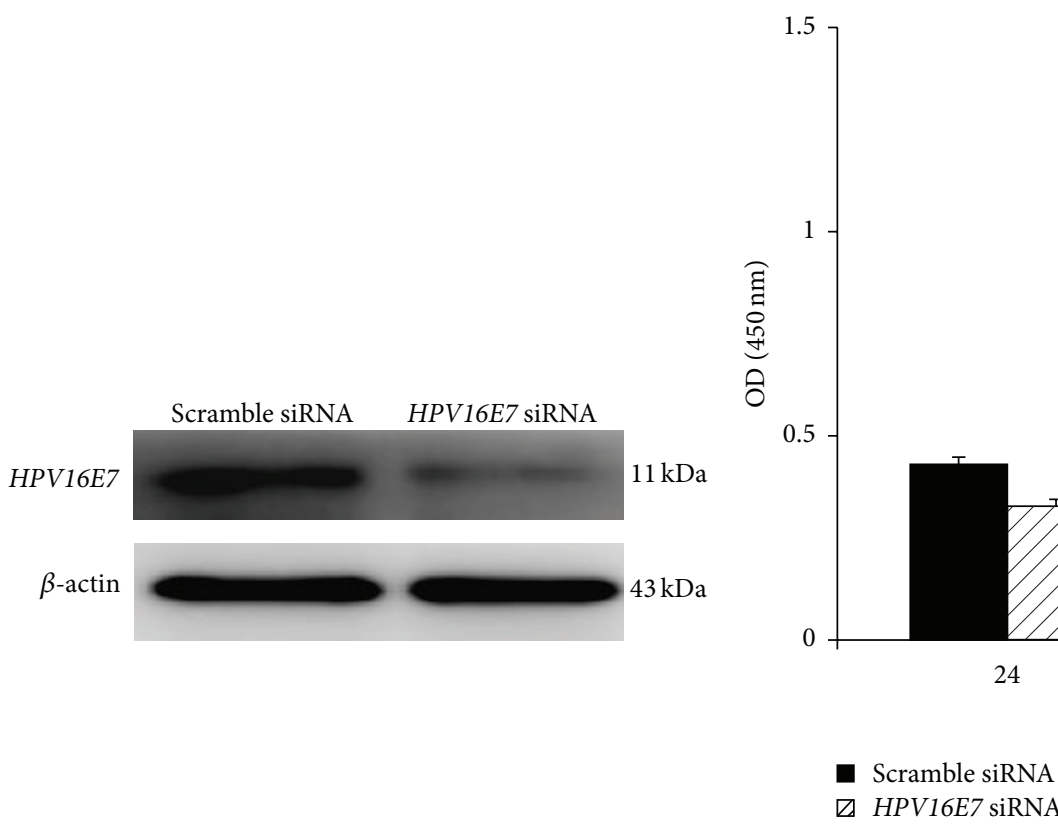

(c)

(d)

Figure 5: Expressions of HPV16E7 mRNA and protein in Hep-2 cells treated with HPV16E7 siRNA. (a) The expression levels of HPV16E7 mRNA were assessed by qRT-PCR $\left(2^{-\Delta \Delta C t}\right.$ method. $2^{-\Delta \Delta C t}$ indicated relative expression level in the treatment group, compared with that in the control group). (b) The protein level of HPV16E7 in the HPV16E7 siRNA group was significantly reduced, compared with the scramble control group $\left({ }^{*} P<0.05\right)$. (c) The expression levels of HPV16E7 protein were detected by Western blotting. (d) Hep- 2 cells were treated with HPV16E7 siRNA and proliferation was measured by CCK- 8 assay at 24 and $72 \mathrm{~h}$ after treatment.

inhibitory effects on $H P V$ oncogene activation and anti$H P V$-associated tumors [28]. Therefore, we hypothesize that oxymatrine may also have an anti- $H P V$ effect that may be able to treat laryngeal cancer. Moreover, oxymatrine has been found to enhance the antitumor immune response, which may also be beneficial for the treatment of laryngeal cancer.

In summary, our in vitro experiments demonstrate that oxymatrine significantly inhibits growth and proliferation and induces apoptosis of laryngeal carcinoma Hep-2 cells. This apoptosis may be in part mediated by a significant blockage in G0/G1 phase. We suggest that the observed effects of oxymatrine are likely associated with the regulation of the HPV16E7 and downstream protein expression. Due to the effective, nontoxic, and natural antitumor properties, oxymatrine is considered to be a likely preventive and curative candidate for laryngeal cancer. Additional studies are required to determine the underlying mechanisms whereby oxymatrine suppresses laryngeal cancer at the molecular level and to provide a theoretical basis for the tumoricidal and clinical utility of oxymatrine.

\section{Conflict of Interests}

The authors declared no conflict of interests. 


\section{Acknowledgment}

This work was supported by the Science and Technology Commission of Shanghai Municipality, China (13ZR1433600).

\section{References}

[1] E. Rudolph, G. Dyckhoff, H. Becher, A. Dietz, and H. Ramroth, "Effects of tumour stage, comorbidity and therapy on survival of laryngeal cancer patients: a systematic review and a metaanalysis," European Archives of Oto-Rhino-Laryngology, vol. 268, no. 2, pp. 165-179, 2011.

[2] X. Li, L. Gao, H. Li et al., "Human papillomavirus infection and laryngeal cancer risk: a systematic review and meta-analysis," Journal of Infectious Diseases, vol. 207, no. 3, pp. 479-488, 2013.

[3] M. E. Manjarrez, R. Ocadiz, L. Valle et al., "Detection of human papillomavirus and relevant tumor suppressors and oncoproteins in laryngeal tumors," Clinical Cancer Research, vol. 12, no. 23, pp. 6946-6951, 2006.

[4] S. Franceschi, N. Muñoz, X. F. Bosch, P. J. F. Snijders, and J. M. M. Walboomers, "Human papillomavirus and cancers of the upper aerodigestive tract: a review of epidemiological and experimental evidence," Cancer Epidemiology Biomarkers and Prevention, vol. 5, no. 7, pp. 567-575, 1996.

[5] K. Munger, B. A. Werness, N. Dyson, W. C. Phelps, E. Harlow, and P. M. Howley, "Complex formation of human papillomavirus E7 proteins with the retinoblastoma tumor suppressor gene product," The EMBO Journal, vol. 8, no. 13, pp. 4099-4105, 1989.

[6] M. Scheffner, B. A. Werness, J. M. Huibregtse, A. J. Levine, and P. M. Howley, "The E6 oncoprotein encoded by human papillomavirus types 16 and 18 promotes the degradation of p53," Cell, vol. 63, no. 6, pp. 1129-1136, 1990.

[7] K. Münger, A. Baldwin, K. M. Edwards et al., "Mechanisms of human papillomavirus-induced oncogenesis," Journal of Virology, vol. 78, no. 21, pp. 11451-11460, 2004.

[8] X.-J. Ying, S.-W. Zhao, J. Qiu, Q. Ye, and A.-H. Sun, "Expression of human papillomavirus type $16 \mathrm{E} 7$ and retinoblastoma proteins in human laryngeal squamous," Academic Journal of Second Military Medical University, vol. 25, pp. 1364-1367, 2004 (Chinese).

[9] F. C. Holsinger, "Swing of the pendulum: optimizing functional outcomes in larynx cancer," Current Oncology Reports, vol. 10, no. 2, pp. 170-175, 2008.

[10] M. Nakayama, O. Laccourreye, F. C. Holsinger, M. Okamoto, and K. Hayakawa, "Functional organ preservation for laryngeal cancer: past, present and future," Japanese Journal of Clinical Oncology, vol. 42, no. 3, pp. 155-160, 2012.

[11] J. R. Guzman, J. S. Koo, J. R. Goldsmith, M. Muhlbauer, A. Narula, and C. Jobin, "Oxymatrine prevents NF- $\kappa$ B nuclear translocation and ameliorates acute intestinal inflammation," Scientific Reports, vol. 3, article 1629, 2013.

[12] L.-G. Lu, M.-D. Zeng, Y.-M. Mao et al., "Oxymatrine therapy for chronic hepatitis B: a randomized double-blind and placebocontrolled multi-center trial," World Journal of Gastroenterology, vol. 9, no. 11, pp. 2480-2483, 2003.

[13] H. G. Fan, L. T. Li, X. J. Zhang et al., "Oxymatrine Downregulates TLR4, TLR2, MyD88, and NF- $\kappa \mathrm{B}$ and protects rat brains against focal ischemia," Mediators of Inflammation, vol. 2009, Article ID 704706, 10 pages, 2009.
[14] M.-Q. Song, J.-S. Zhu, J.-L. Chen et al., "Synergistic effect of oxymatrine and angiogenesis inhibitor NM-3 on modulating apoptosis in human gastric cancer cells," World Journal of Gastroenterology, vol. 13, no. 12, pp. 1788-1793, 2007.

[15] Z. Lin, C.-F. Huang, X.-S. Liu, and J. Jiang, "In vitro anti-tumour activities of quinolizidine alkaloids derived from Sophora flavescens Ait," Basic \& Clinical Pharmacology and Toxicology, vol. 108, no. 5, pp. 304-309, 2011.

[16] Y. H. Dong, H. L. Xi, Y. Y. Yu, Q. H. Wang, K. Jiang, and L. Z. $\mathrm{Li}$, "Effects of oxymatrine on the serum levels of $\mathrm{T}$ helper cell 1 and 2 cytokines and the expression of the $S$ gene in hepatitis $B$ virus $S$ gene transgenic mice: a study on the anti-hepatitis B virus mechanism of oxymatrine," Journal of Gastroenterology and Hepatology, vol. 17, no. 12, pp. 1299-1306, 2002.

[17] N. L. Chai, Q. Fu, H. Shi et al., "Oxymatrine liposome attenuates hepatic fibrosis via targeting hepatic stellate cells," World Journal of Gastroenterology, vol. 18, no. 31, pp. 4199-4206, 2012.

[18] H. Liu, Y. Sun, Y. Gao, F. Chen, M. Xu, and Z. Liu, "The analgesic effect and mechanism of the combination of sodium ferulate and oxymatrine," Neurochemical Research, vol. 35, no. 9, pp. 1368-1375, 2010.

[19] S.-C. Ma, J. Du, P. P.-H. But et al., "Antiviral Chinese medicinal herbs against respiratory syncytial virus," Journal of Ethnopharmacology, vol. 79, no. 2, pp. 205-211, 2002.

[20] Y.-P. Wang, W. Zhao, R. Xue et al., "Oxymatrine inhibits hepatitis B infection with an advantage of overcoming drugresistance," Antiviral Research, vol. 89, no. 3, pp. 227-231, 2011.

[21] J.-S. Zhu, Z.-P. Xu, M.-Q. Song, and Q. Zhang, "Effect of oxymatrine combined with low dose 5-Fu on lymphatic vessel and microvascular endothelial cell growth of gastric cancer in a severe combined immunodeficient mouse orthotopic implantation model," European Journal of Inflammation, vol. 9, no. 1, pp. 45-51, 2011.

[22] Y. Zhang, B. Piao, B. Hua et al., "Oxymatrine diminishes the side population and inhibits the expression of beta-catenin in MCF7 breast cancer cells," Medical Oncology, vol. 28, no. 1, pp. S99S107, 2011.

[23] G. Song, Q. Luo, J. Qin, L. Wang, Y. Shi, and C. Sun, "Effects of oxymatrine on proliferation and apoptosis in human hepatoma cells," Colloids and Surfaces B: Biointerfaces, vol. 48, no. 1, pp. $1-5,2006$.

[24] Q. Ling, X. Xu, X. Y. Wei et al., "Oxymatrine induces human pancreatic cancer PANC-1 cells apoptosis via regulating expression of Bcl-2 and IAP families, and releasing of cytochrome C," Journal of Experimental \& Clinical Cancer Research, vol. 30, no. 1, article 66, 2011.

[25] K. Münger, J. R. Basile, S. Duensing et al., "Biological activities and molecular targets of the human papillomavirus E7 oncoprotein," Oncogene, vol. 20, no. 54, pp. 7888-7898, 2001.

[26] D. L. Jones and K. Münger, "Interactions of the human papillomavirus E7 protein with cell cycle regulators," Seminars in Cancer Biology, vol. 7, no. 6, pp. 327-337, 1996.

[27] H. J. Huang, O. L. Zegarra-Moro, D. Benson, and D. J. Tindall, "Androgens repress Bcl-2 expression via activation of the retinoblastoma (RB) protein in prostate cancer cells," Oncogene, vol. 23, no. 12, pp. 2161-2176, 2004.

[28] J. Zheng, Y.-P. Deng, C. Lin, M. Fu, P.-G. Xiao, and M. $\mathrm{Wu}$, "Arsenic trioxide induces apoptosis of HPV16 DNAimmortalized human cervical epithelial cells and selectively inhibits viral gene expression," International Journal of Cancer, vol. 82, no. 2, pp. 286-292, 1999. 


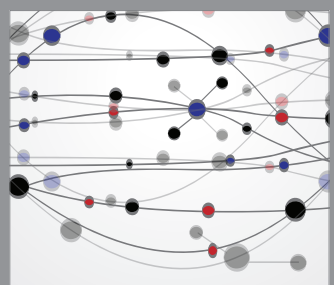

The Scientific World Journal
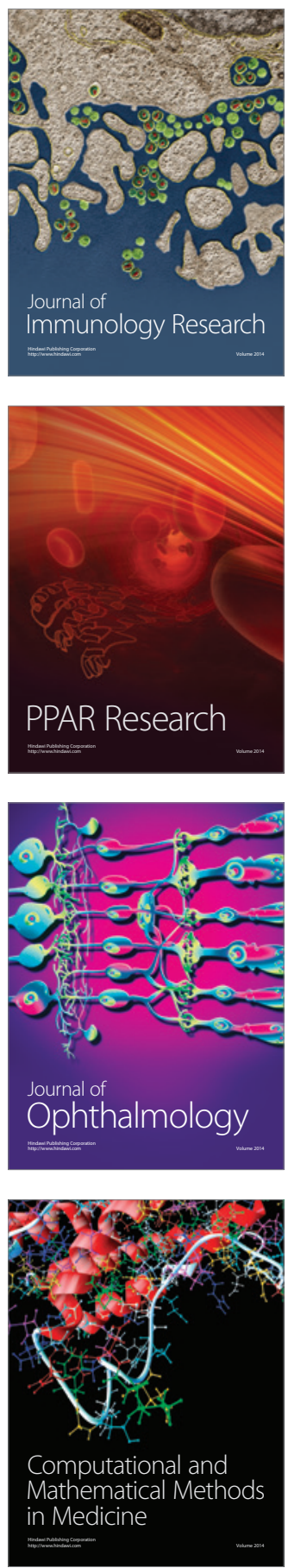

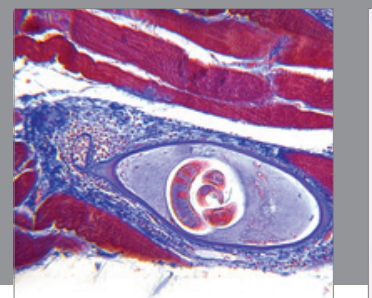

Gastroenterology

Research and Practice
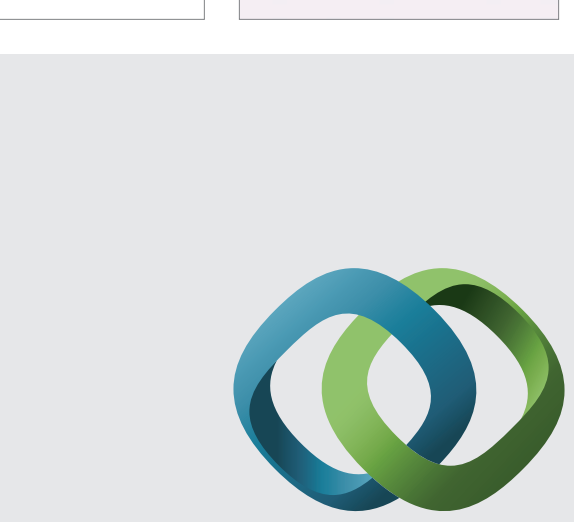

\section{Hindawi}

Submit your manuscripts at

http://www.hindawi.com
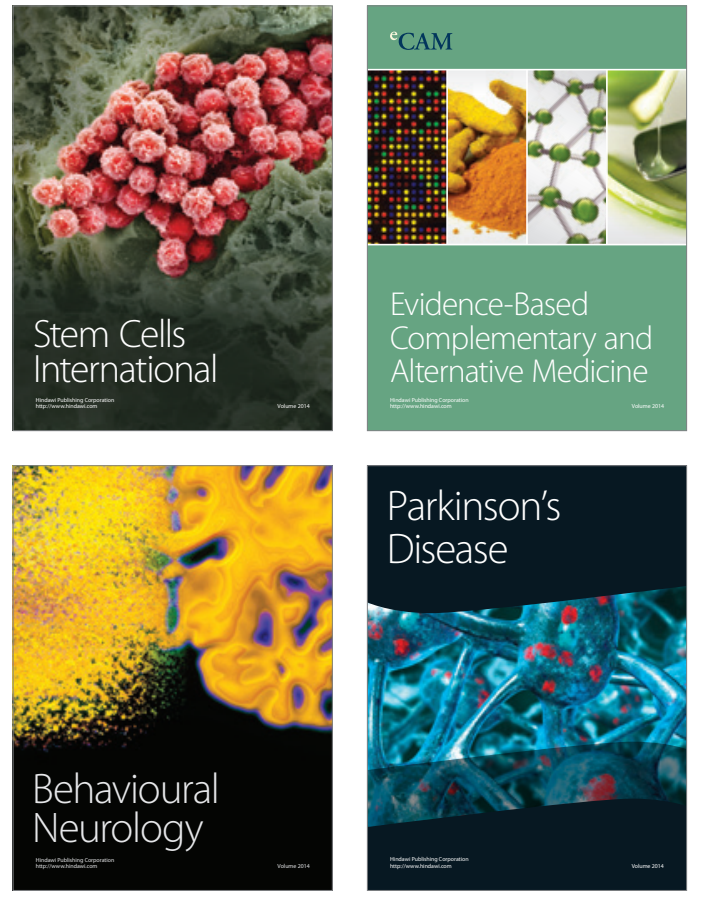
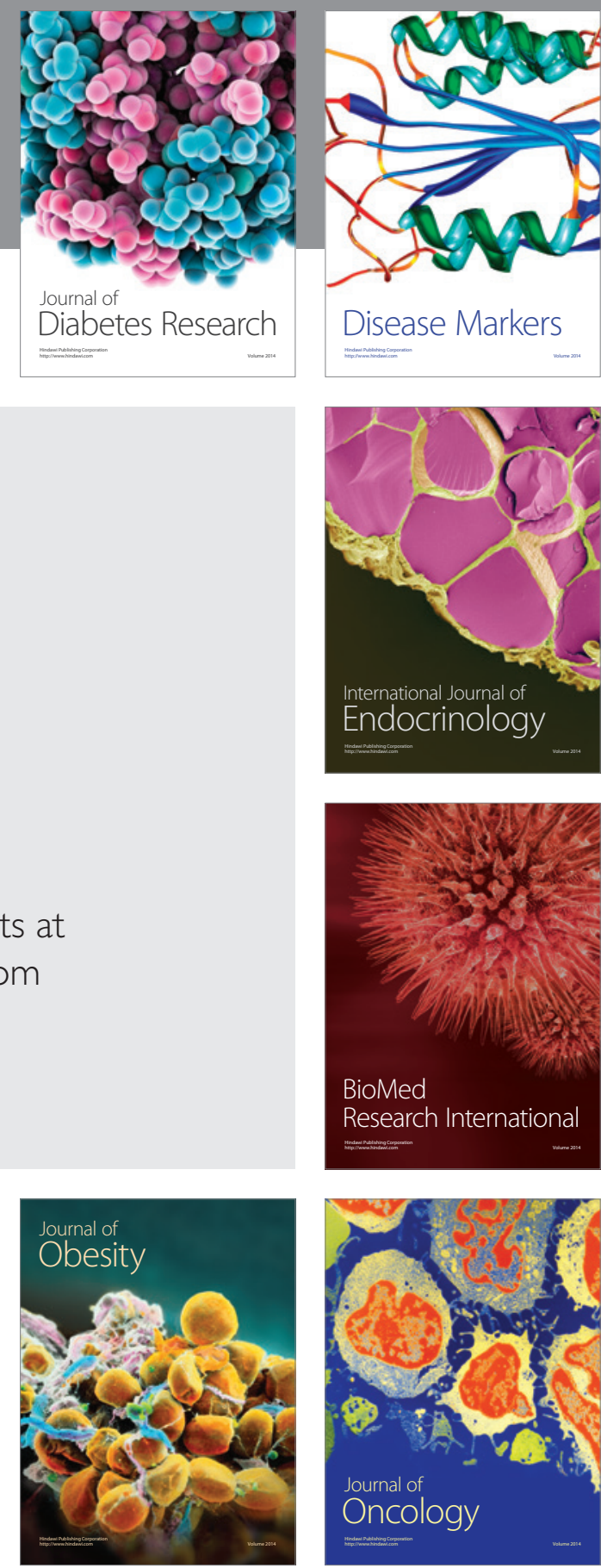

Disease Markers
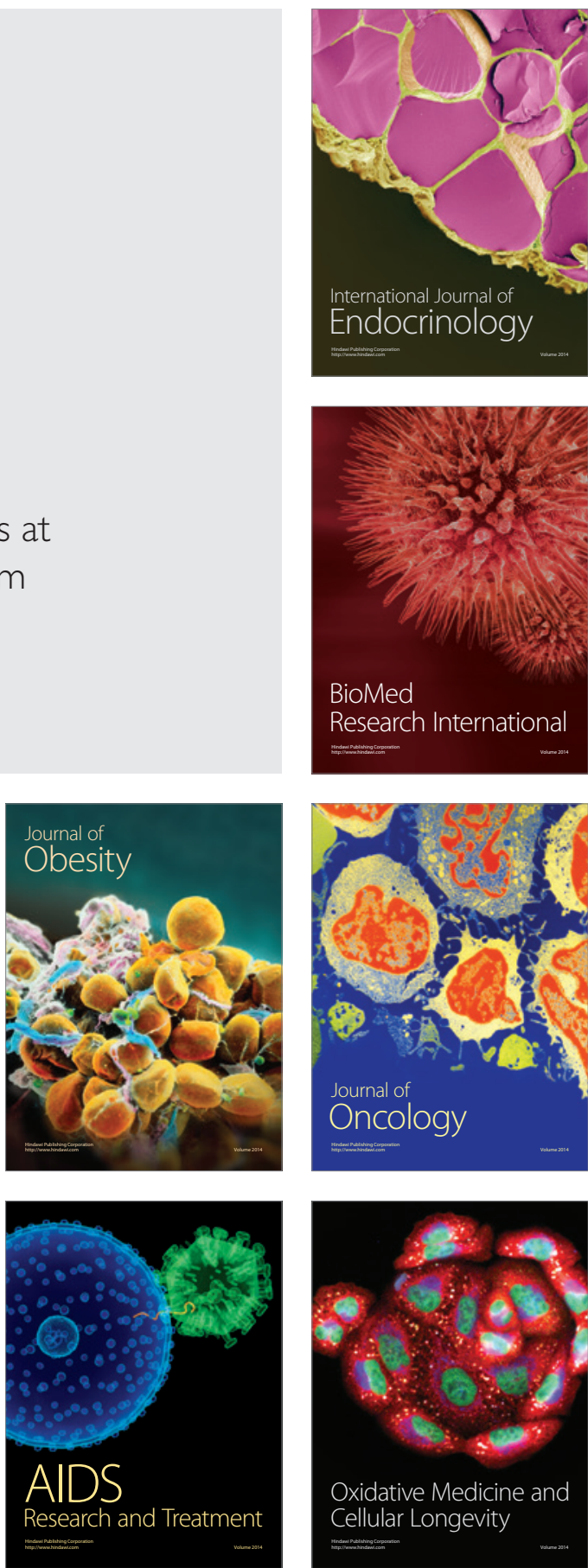